\title{
How do relational and personal attributes affect trust in adolescent friendship: An exploratory model
}

\author{
Ainin Rahmanawati ${ }^{1}$, Flaviana Rinta Ferdian ${ }^{2}$, Tria Widyastuti ${ }^{3}$, Faturochman ${ }^{4}$, Wenty \\ Marina Minza ${ }^{5}$ \\ 1,2,3,4,5 Center for Indigenous and Cultural Psychology, Faculty of Psychology, Universitas Gadjah Mada, \\ Indonesia \\ 1aininrhmn@gmail.com., ${ }^{2}$ flaviana.rinta@gmail.com., ${ }^{3}$ triawidya06@gmail.com., ${ }^{4}$ faturochman@ugm.ac.id., \\ 5wminza@ugm.ac.id
}

ARTICLE INFO

Article history

Received 18 March 2019

Revised 9 January 2020

Accepted 9 January 2020

\section{Keywords}

benevolence

closeness

competence

integrity

reciprocity

support

trust

\begin{abstract}
Trust is an important aspect in human relationship. According to previous research trust is influenced by 2 main attributes: personal (benevolence, integrity, and competence) and relational (support, closeness, and reciprocity) attribute. The study aimed to find a preliminary model to explain the association of personal and relational attributes in adolescent friendship. Two hundred and twenty participants $($ male $=44.09 \%$ and female $=55.91 \%$ ) participated in the study. A survey method was used to collect the data. The design of this study was correlational design. Results from enter method in regression analysis show that six factors of personal and relational attributes influence trust at $44.5 \%$. However, closeness had no significant influence on trust, so closeness was not included in the next analysis, the sequential analysis. The result shows that the relational attribute has higher influence on trust than personal attribute. Support and reciprocity factors which belong to relational attribute, has a higher contribution to trust in adolescent friendship than benevolence, integrity and competence - the latter three factors belonging to the personal attribute. Therefore building trust in friendship requires an emphasis on relational attributes of trust, especially that of support and reciprocity factors.
\end{abstract}

\section{Introduction}

Trust is an essential aspect in a social life and interdependent society (Igarashi et al., 2008; Talwar \& Renaud, 2010). We believe in people who grow and process the foods and medicines that we consume; we depend on the person who made the house we live in; we believe in the person who hold our money and our investment; and we believe in the government that keeps us from aggressors. In general, in every phase of our lives, we will rely on others to behave according to our expectations and hope that our expectation will be fulfilled. High levels of trust in society facilitates a fast and wide dissemination of information, (Lindström, 2005; Yip et al., 2007), which functions to reduce uncertainty (Tschannen-Moran \& Hoy, 2000), develop and maintenance happiness and well-functioning relationships (Crosnoe et al., 2003; Simpson, 2007). Without trust, the world would be more painful and empty (Shultz, 2007; Simmel, 2011).

Even thought trust is important in life, it has received relatively limited attention because of its complex multidimensional construct. Apart from the concept of trust being based on various disciplines, the variety of stages that trust develops within different types of relationships, makes trust a challenging concept to study (Simpson, 2007). There are 
relationships where trust persists for long periods of time, while in others, trust is prone to conflict. Therefore, trust is unstable and can change rapidly in both directions (TschannenMoran \& Hoy, 2000).

Trust is a state where a person is willing to be vulnerable on the basis of positive expectation towards another person (Mayer et al., 1995). Khodyakov (2007) noted that trust is created from a process of maintaining quality in social relation. In line with the definition, Rotenberg (2010) defines trust as a protection against doubt to create a good relationship between each other. These definitions of trust focuses on trust at the interpersonal level, which can be classified in two dimensions, cognitive and affective (Ferris et al., 2010; McAllister, 1995). The cognitive forms of trust consist of perceiving others as reliable, honest, fair, and having integrity. Meanwhile the affective dimension includes a specific relationship with another, which can cause the other party to show concern about a person's welfare.

The trust model from Mayer et al (1995) is one of the models that is quite prominent, which explains that personal factors of a trustee and trustor's propensity leads to trust. Propensity is a condition where a person places general trust towards others, which influences how much trust one exerts towards the trustee. There are three personal factors which influence trust: ability/competence, benevolence, and integrity. This model is similar to the framework on trust in the context of leadership (Burke et al., 2007), trust in online shopping (Connolly \& Bannister, 2008), and trust in the organization context (Bews \& Martins, 2002; Chong et al., 2003).

Benevolence is when a trustee does something good to the trustor without expecting any profit (Mayer et al., 1995; Tschannen-Moran \& Hoy, 2000). From the trustor's perspective, benevolence is the confidence that one's wellbeing will be protected and not hurt by the trusted party. Meanwhile, competence/ability is a set of skills, abilities, and characteristics that enables a person to exert influence over specific aspects. Competence can be interpreted as the personal abilities in individuals as part of the acquisitions and used as knowledge. In a social context, the competence of participants is the knowledge of individuals to place awareness in different situations, as well as individual knowledge in people around (Rotenberg, 2010). Benevolence is not enough, sometimes a good person who does not have enough skills, will not be trusted (Tschannen-Moran \& Hoy, 2000). So, competence is also a factor that influences trust. Finally, integrity is defined as how far a trustor perceives the trustee's act in accordance with the set of values the trustor holds (Mayer et al., 1995).

Various factors contribute to the development of trust. The quality of a trusted party, consisting of one's reliability, competence, and integrity (personal attribute), is often used as criteria in developing trustworthiness (Mayer et al., 1995). However, research conducted by Faturochman \& Minza (2014) found that trust is influenced by two major attributes, the personal and relational attribute. Relational attributes mentioned in the study consists of support, closeness, and reciprocity (Faturochman \& Minza, 2014). Support can be defined as information which leads people to believe that he or she is being cared, loved, and appreciated (Kumalasari \& Ahyani, 2012). Closeness can be described as the extent to which the thoughts, affect, and behaviors of trustor and trustee are interrelated (Laursen et al., 2000). Close relationship between two persons determine the quality of trust. Thus trust will increase when the trustor and trustee have a close relationship (Faturochman \& Minza, 2014). Reciprocity can be defined as the extent to which mutuality and cooperation figure the relationship (Laursen et al., 2000).

Yet, trust is influential in the fabrication of social life especially in interpersonal relation. In interpersonal relations, trust becomes a key in developing and maintaining happiness and well-functioning relationships (Crosnoe et al., 2003; Simpson, 2007). When a relationship is based a trust, the parties involved will have a strong desire to continue the relationship (Simpson, 2007; Warris \& Rafique, 2009).

In this research, we will mainly discuss trust at the interpersonal level, especially in the context of friendship, which is a basic human need (Carroll, 2002). In general, a friend is 
someone who can be trusted, who can be invited to enjoy togetherness, and to share life experiences (Turner, 2002). However, friendship itself is a social phenomenon that is part of socialization in human life with the aim of improving their social circle for several reasons, such as sharing, enjoying togetherness, and getting some emotional comfort (Warris \& Rafique, 2009), an internal need for humans and a tendency to depend on a person (Carroll, 2002). Thus friendship is a human's need in interacting with others to share and support (Hurlock, 2004).

Friendship and trust are strongly related concepts because there is no relationship that can survive without trust (Warris \& Rafique, 2009). Trust is a cornerstone on the way we interact with others (Rotenberg et al., 2005), and it causes high-quality interactions and confidence in friendship (Bove \& Johnson, 2001). This makes trust in friendship important because it will lead to greater social support and better quality of life (Demerouti et al., 2001; Lunsky \& Benson, 2001). Individuals in reciprocated friendships have more positive quality of friendship than non-reciprocated friendships. Reciprocated friendship correlate with less conflict in friendship (Linden-Andersen et al., 2009). Closeness is most common root terms in the study of interpersonal relationship (Johnson et al., 2009), as it is related with the commitment to the continuation of relationship (Simpson, 2007; Warris \& Rafique, 2009). Support is related with good quality friendship, and enhances psychosocial well-being (Ciairano et al., 2007).

This study aimed at finding a preliminary model which can explain how trust is influenced by personal attributes (benevolence, integrity, and competence) and relational attributes (support, closeness, and reciprocity) in adolescent friendship. The hypothesis of this study is relational attributes play a major factor on building trust, supported by personal attributes of trustee.

\section{Method}

This study was conducted in Yogyakarta. In this study, survey method was used in collecting the data.

\section{Participants}

Participants in this study were 220 students from the Faculty of Psychology and Faculty of Engineering at Universitas Gadjah Mada (Indonesia). A breakdown by gender yielded 123 women $(55.9 \%)$ and 97 men $(41.36 \%)$ representing the balanced distribution of gender in this student population. The mean age of the participants is 19 years 2 months with a range from 17 to 21 years old.

\section{Procedure}

The participants completed a likert scale in Bahasa Indonesia, the national language of participants. The likert scale was developed from the results research conducted by Faturochman \& Minza (2014), measuring cognitive, affective, and behavioral dimensions of each variable in this study. The intrument consists of three scales measuring the following variables: personal trustworthiness (benevolence, competence, integrity), relational trustworthiness (support, closeness, reciprocity), and trust. Benevolence, competence, and integrity are considered personal attributes influencing trust, while support, closeness, and reciprocity are considered relational attributes influencing trust. The participants as a trustor (a trusting party) were asked to imagine a specific person, either a best friend or a close friend, to help them decide their answer to the questions that assess the personal characteristics of trustee (a party to be trusted) which includes benevolence, competence, and integrity. The participants were also asked about the relational attributes of trustee such as support, closeness, and reciprocity. 


\section{Instrument}

Personal trustworthiness scale consists of three subscales as follows:

Benevolence Subscale. The benevolence subscale consists of 5 items. It was used to assess the personal characteristic of the trustee, especially in relation to the extent to the trustor believes that the trustee will treat the trustor well. Participants were asked to rate their agreement on statements relating to their friend as a trustee, such as "he/she is friendly" and "he/she cheers the other who is sad."

Competence Subscale. The competence subscale was used to measure the competence skill of a trustee. It consists of 6-items. The sample items are "he/she is a broad minded person" and "he/she is a well experienced in his/her field."

Integrity Subscale. The integrity subscale consists of 5-item. The items measure how far a trustor sees that the trustee's behavior is in accordance with principles that the trustor finds acceptable. The question in this scale such as "he/she keeps a promise" and "he/she keep the secret."

Relational trustworthiness scale consists of three subscales as follows:

Support Subscale. The support was used to assess how the trustee support the trustor. This subscale consists of 6-item. Participants asked to rate their agreement on statements related with their friend as a trustee such as "he/she motivates me" and "he/she gives a suggestion to me."

Closeness Subscale. The closeness subscale consists of 5 items. The items which assesses the interconnectedness between the trustee and trustor. Participants rated to what extent they agreed or disagreed with the statements related to his/her friend, for instance "he/she is close to me."

Reciprocity Subscale. The reciprocity subscale was used to assess the extent of mutuality and cooperation between the trustee and trustor. This subscale consists of 5 items. Participants rated how far their agreed on statements concerning their friend, for instance, "he/she and I understand each other" and "he/she and I believe each other."

The trust scale is a 6-item scale which assesses the extent of the trustor's tendency to trust a trustee. Sample of statements is "I can fully trust my friend."

The response format was a 7-point likert-type rating scale (ranging from $1=$ strongly disagree to $7=$ strongly agree) reflecting the agreement or disagreement of subject in a statement of items. The attributes were tested and has a reliability value of more than .7, which means the measuring instrument can explain the attributes; while the item-total correction range was .3 - .6. Table 1 shows the psychometric properties of the instruments.

Table 1

Result of Internal Consistency Test

\begin{tabular}{lllll}
\hline Variable & Factor & $\begin{array}{l}\text { Number of } \\
\text { item }\end{array}$ & Item-Total Correlation & Alpha \\
\hline Personal & Benevolence & 6 & $.55-.75$ & .85 \\
trustworthiness & Competence & 5 & $.48-.69$ & .80 \\
& Integrity & 5 & $.42-.70$ & .78 \\
Relational & Support & 6 & $.50-.75$ & .80 \\
trustworthiness & Closeness & 5 & $.72-.83$ & .90 \\
& Reciprocity & 5 & $.71-.84$ & .92 \\
Trust & & 6 & $.37-.58$ & .74 \\
\hline
\end{tabular}




\section{Data Analysis}

The correlation and regression analysis were used to analyze data with SPSS. First, the correlation analysis with Pearson correlation was done between the personal attribute (benevolence, competence, and integrity) and relational attribute (support, closeness, and reciprocity) as an independent variable with trust. Then enter method in regression analysis was used in the next analysis to find out the contribution of all variables together on trust. After that, sequential analysis was applied to explore the effect of personal and relational attributes on trust.

\section{Results}

\section{Correlation Analysis}

The correlation analysis with Pearson Correlation in Table 2 show that all of the factors were positively correlated with trust. All of the correlations were significant at .01 alpha level (2tailed). The means that the six factors can explain trust. The relational attributes which comprise of support $(r=.62)$, closeness $(r=.51)$, and reciprocity $(r=.56)$ have higher correlation coefficient than the personal attributes which comprises of benevolence $(r=.46)$, competence $(r=.25)$, and integrity $(r=.46)$. Support $(r=.62)$ has the highest correlation coefficient with trust among the others factors. Meanwhile competence $(r=.25)$ has the lowest correlation coefficient among the others.

Table 2

\section{Mean and Standard Deviation of Factors and Its Correlation with Trust}

\begin{tabular}{lccc}
\hline Factor & Mean & $S D$ & $r$ \\
\hline Benevolence & 32.55 & 5.43 & $.46^{* *}$ \\
Competence & 24.81 & 4.55 & $.25^{* *}$ \\
Integrity & 27.97 & 4.14 & $.46^{* *}$ \\
Support & 30.42 & 5.74 & $.62^{* *}$ \\
Closeness & 29.44 & 4.71 & $.51^{* *}$ \\
Reciprocity & 28.71 & 4.77 & $.56^{* *}$ \\
\hline
\end{tabular}

$* * p<.01$

\section{Regression Analysis}

The results of regression analysis with enter method in Table 3 show that all factors together influence trust at $44.5 \%$. In this analysis, closeness has no significant influence on trust $(\beta=$ $-.01 ; p=.981)$. Therefore closeness was not used in the next analysis.

Table 3

The Result of Enter Method in Regression Analysis

\begin{tabular}{|c|c|c|c|c|c|}
\hline Factors & $\begin{array}{l}\text { Dependent } \\
\text { Variable }\end{array}$ & Beta & $F$ & $p$ & $R^{2}$ \\
\hline Benevol & \multirow{6}{*}{ Trust } & $.15^{*}$ & \multirow{6}{*}{28.51} & \multirow{6}{*}{.00} & \multirow{6}{*}{$44.5 \%$} \\
\hline Compet & & $-.16^{*}$ & & & \\
\hline Integrity & & $.15^{*}$ & & & \\
\hline Support & & $.38 *$ & & & \\
\hline Closene & & -.01 & & & \\
\hline Recipro & & $.21 *$ & & & \\
\hline
\end{tabular}


The enter method was also used to explain how the other five attributes influence trust. Table 4 and Table 5 show that relational attributes have higher influence $(41.5 \%)$ than personal attributes $(30.1 \%)$.

Table 4

The Result of Enter Method in Regression for Analysis of Personal Attributes in Regression Analysis

\begin{tabular}{llllll}
\hline Factor & $\begin{array}{l}\text { Dependent } \\
\text { Variable }\end{array}$ & Beta & $F$ & $p$ & $R^{2}$ \\
\hline Benevolence & & $.36^{*}$ & & .00 & \\
Competence & Trust & $-.12^{*}$ & 28.51 & .00 & .301 \\
Integrity & & $.36^{*}$ & & .00 & \\
\hline$* p<.05 ; * * p<.01$ & & & &
\end{tabular}

Table 5

The Result of Enter Method in Regression for Analysis Relational Attributes

\begin{tabular}{clclll}
\hline Factor & $\begin{array}{l}\text { Dependent } \\
\text { Variable }\end{array}$ & Beta & $F$ & $p$ & $R^{2}$ \\
\hline Support & Trust & $.43^{*}$ & 76.84 & .00 & .415 \\
Reciprocity & .26* & .00 & .4 \\
\hline${ }^{*} p<.05 ;{ }^{* *} p<.01$ & & & & &
\end{tabular}

\section{Sequential Analysis}

Sequential analysis was used to explore the model of personal and relational attributes on trust. As shown in Table 6, support and reciprocity has a high influence on trust $\left(R^{2}=41.5 \%\right)$. The enter method which involve all of the factors, shows that contribution of five factors (support, reciprocity, benevolence, integrity, and competence) is $44.5 \%$ (see Table 3). Using sequential analysis, the $R^{2}$ change between the previous and latest analysis was only $3.0 \%$. As the main variable, relational attribute explains trust at $41.5 \%$.

Table 6

The Result of Sequential Analysis

\begin{tabular}{lllllr}
\hline Factor & $\begin{array}{l}\text { Dependent } \\
\text { Variable }\end{array}$ & $F$ & $t$ & $R^{2}$ & $R^{2}$ change \\
\hline Support & Trust & $76.84^{* *}$ & $6.07^{* *}$ & .415 & \\
Reciprocity & & & $3.67^{* *}$ & & \\
Support & & $34.37^{* *}$ & $4.48^{* *}$ & & .03 \\
Reciprocity & & $2.91^{* *}$ & & .445 & \\
Benevolence & Trust & & $2.29^{* *}$ & .44 & \\
Competence & & & $2.48^{* *}$ & & \\
Integrity & & & $2.18^{* *}$ & &
\end{tabular}

\section{Discussion}

The main purpose of this study was to explore the role of relational and personal attribute toward trust in adolescent friendship. The findings indicate that trust in adolescent friendship is influenced by relational and personal attributes. This result is consistent with Glanville \& Paxton (2007), which found that people will trust others based on both personal character and relational aspects. Specifically, the findings explain that relational attributes including support and reciprocity play the main role in forming trust in adolescent friendship, meanwhile personal attributes including benevolence, integrity, and competence play supporting roles. In other words, a good relationship has more contribution than personal 
attribute in forming trust. This finding strengthens the prior study from Faturochman \& Minza (2014) that a good quality personal characteristic of the trustee is not sufficient in forming trust, because there must be a good relationship between actors. Rus \& Iglič (2005) also found that quality of trust arises when trustor and trustee have a close relationship.

One of the possible reasons of why relational attributes becomes a main factor in adolescent friendship's trust in this research is because of Indonesian culture, which is predominantly collectivist. Hofstede (2011) stated that less developed and Eastern countries tend to be a collectivistic country. As a collectivist society, Indonesian people are integrated with their group and have a strong attachment (Hofstede, 2011), and it is necessary to first build a relationship and form trust between people (de Mooij \& Hofstede, 2010). According to its characteristic as collectivist society, Indonesia tends to place relational attributes first in comparison to personal attribute in forming trust.

\section{The role of relational attributes}

Among three factors in relational attributes, support and reciprocity have significant contribution towards trust in adolescent friendship; meanwhile closeness has no significant contribution. In this model, support has higher contribution toward trust in adolescent friendship in comparison with reciprocity. High quality friendship is appraised as a source of support for adolescents (Damon \& Lerner, 2008) and support from the environment has a positive correlation with trust (Salazar, 2015). It is possible that social support has an important impact on trust because it can provide a shield from stress. A study from Ying (2008) shows that social support from a friend protects adolescents from emotional exhaustion or stress. Emotional support, which is included as a relational attribute, encourages the formation of trust in friendship (Weber et al., 2004).

The role of reciprocity toward trust in adolescent friendship is strengthened by finding from Das \& Teng (2004) and Tanis \& Postmes (2005), showing that reciprocity is a fundamental factor in maintaining trust. Reciprocity is returning an act i.e. good deeds are rewarded and bad deeds are punished (Fehr \& Gächter, 2011), and a manifestation of the equality matching model of relation. Reciprocity in friendship makes people feel comfortable with the mutual connection they built. Reciprocity is also an important aspect toward trust in adolescent friendship because friendship is an interdependent relation. In interdependence theory, people develop trust depends not only based on personal traits but also on the historical relation with people (Van Lange \& Balliet, 2015). If reciprocity can be achieved, where one party can accomplish and be responsive to the other party's need, then trust will follow. In ongoing relationships, partner's actions representing reciprocity are more important than the person's trait. Interdependent theory stated that trust lies in both actors' hands.

As shown previously, the relational attributes of support and reciprocity have an influence on trust; while closeness does not. Nielson (1998) found that closeness is only needed in the beginning of a relationship, while support and reciprocity are needed to maintain the relationships.

\section{The role of personal attributes}

Despite the importance of relational attributes in building trust, the quality of a trustee comprising of benevolence, integrity, and competence remains a significant factor in building trust. This finding is consistent with Xie \& Peng (2009) who found that benevolence, integrity, and competence has a major role in repairing trust in customers.

The results show benevolence as factor which contributes in forming trust in adolescent friendship. A prior study in different subject (preschooler children) confirms the above result (Johnston et al., 2015; Landrum et al., 2013). The study found children weigh benevolence when choosing who can be trusted. In another context, a client is more concerned with benevolence than the competency of consultants, especially for long-term collaboration (Ko, 
2010). Wu et al. (2014) also found the same result that benevolence has a higher impact on trust in continuing online social networks.

Apart from benevolence, integrity as a personal attribute of a trustee also leads to trust. Butler (1991) revealed that integrity is one of the basis of trust, which includes honesty and moral character (i.e truthfulness). A person who has integrity will tend to encourage others to be close and trust them. In friendship, a person who has integrity is believed to be a capable person who can be trusted. Palanski et al. (2011) also found that integrity is defined as the consistency of one's behavior, is related with, and will lead to trust at the individual level and at the group level.

However, this study also found that competence as a personal characteristic of the trustee has negative influence on trust. This can be explained by findings from Butler (1991) which found that competence is important and salient condition only in contexts such as in hierarchical relationships (as a superior's downward trust towards his or her staff). Trust in adolescent friendship is a relation which on the most part is equivalent. Parallel to the finding, Ko (2010) mentions that trust towards others no longer focuses on competence.

The implication of this research is that building trust in friendship requires an emphasis on relational attributes of trust, especially support and reciprocity. Along the emphasis on relational attributes, personal attributes of trust (benevolence, integrity, and competence) are also needed to support the foundation of trust in friendship. The limitations of this study lies in the number of subjects. Only 220 subjects participated in this research, and all of which are university students. Therefore, this research cannot be generalized in larger population of adolescents outside the university student population. To obtain a more comprehensive concept of trust in Indonesia, further research needs to include participants which represent a larger variation of adolescents.

\section{Conclusion}

This study explored how personal and relational attributes influenced trust in adolescent friendship. The results show relational attribute is the main factor in building trust, meanwhile personal attributes play a supporting role. The findings indicate that in forming trust in friendship, building a good relation through support and reciprocity is more important than constructing good personal characteristics such as benevolence, integrity, and competence.

\section{References}

Bews, N., \& Martins, N. (2002). An evaluation of the facilitators of trustworthiness. SA Journal of Industrial Psychology, 28(4), 14-19. https://doi.org/10.4102/sajip.v28i4.70

Bove, L. L., \& Johnson, L. W. (2001). Customer relationships with service personnel: Do we measure closeness, quality or strength? Journal of Business Research, 54(3), 189197. https://doi.org/10.1016/S0148-2963(00)00122-3

Burke, C. S., Sims, D. E., Lazzara, E. H., \& Salas, E. (2007). Trust in leadership: A multilevel review and integration. The Leadership Quarterly, 18(6), 606-632. https://doi.org/10.1016/j.leaqua.2007.09.006

Butler, J. K. (1991). Toward understanding and measuring conditions of trust: Evolution of a conditions of trust inventory. Journal of Management, 17(3), 643-663. https://doi.org/10.1177/014920639101700307

Carroll, M. N. (2002). Gender differences in trust and loyalty within single sex friendships. Loyola University.

Chong, B., Yang, Z., \& Wong, M. (2003). Asymmetrical impact of trustworthiness attributes on trust, perceived value and purchase intention: A conceptual framework for cross- 
cultural study on consumer perception of online auction. Proceedings of the 5th International Conference on Electronic Commerce - ICEC '03, 213-219. https://doi.org/10.1145/948005.948033

Ciairano, S., Rabaglietti, E., Roggero, A., Bonino, S., \& Beyers, W. (2007). Patterns of adolescent friendships, psychological adjustment and antisocial behavior: The moderating role of family stress and friendship reciprocity. International Journal of Behavioral Development, 31(6), 539-548. https://doi.org/10.1177/0165025407080573

Connolly, R., \& Bannister, F. (2008). Factors influencing Irish consumers' trust in internet shopping. Management Research News, 31(5), 339-358. https://doi.org/10.1108/01409170810865154

Crosnoe, R., Cavanagh, S., \& Elder, G. H. (2003). Adolescent friendships as academic resources: The intersection of friendship, race, and school disadvantage. Sociological Perspectives, 46(3), 331-352. https://doi.org/10.1525/sop.2003.46.3.331

Damon, W., \& Lerner, R. M. (2008). Child and adolescent development. New York: John Wiley \& Sons, Inc.

Das, T. K., \& Teng, B.-S. (2004). The risk-based view of trust: A conceptual framework. Journal of Business and Psychology, 19(1), 85-116. https://doi.org/10.1023/B:JOBU.0000040274.23551.1b

de Mooij, M., \& Hofstede, G. (2010). The Hofstede model: Applications to global branding and advertising strategy and research. International Journal of Advertising, 29(1), 85110. https://doi.org/10.2501/S026504870920104X

Demerouti, E., Bakker, A. B., Nachreiner, F., \& Schaufeti, W. B. (2001). The job-demandsresources model of burnout. Journal of Applied Psychology, 86(3), 499-512. https://doi.org/10.1037/0221-9010

Faturochman, \& Minza, W. M. (2014). Exploring personal and relational trustworthiness. Unpublished Manuscript.

Fehr, E., \& Gächter, S. (2011). Fairness and retaliation: The economics of reciprocity. In Advances in Behavioral Economics (pp. 510-532). Princeton University Press. https://doi.org/10.2139/ssrn.229149

Ferris, D. L., Lian, H., Pang, Fi. X. J., \& Keeping, L. M. (2010). Self-esteem and job performance: The moderating role of self-esteem contingencies. Personnel Psychology, 63(3), 561-593. https://doi.org/10.1111/j.1744-6570.2010.01181.x

Glanville, J. L., \& Paxton, P. (2007). How do we learn to trust? A confirmatory tetrad analysis of the sources of generalized trust. Social Psychology Quarterly, 70(3), 230242. https://doi.org/10.1177/019027250707000303

Hofstede, G. (2011). Dimensionalizing cultures: The Hofstede model in context. Online Readings in Psychology and Culture, 2(1), 1-26. https://doi.org/10.9707/23070919.1014

Hurlock, E. B. (2004). Psikologi perkembangan (Developmental psychology). PT. Gramedia Pustaka.

Igarashi, T., Kashima, Y., Kashima, E. S., Farsides, T., Kim, U., Strack, F., Werth, L., \& Yuki, M. (2008). Culture, trust, and social networks. Asian Journal of Social Psychology, 11(1), 88-101. https://doi.org/10.1111/j.1467-839X.2007.00246.x

Johnson, A. J., Haigh, M. M., Craig, E. A., \& Becker, J. A. H. (2009). Relational closeness: Comparing undergraduate college students' geographically close and long-distance friendships. Personal Relationships, 16(4), 631-646. https://doi.org/10.1111/j.14756811.2009.01243.x

Johnston, A. M., Mills, C. M., \& Landrum, A. M. (2015). How do children weigh competence and benevolence when deciding whom to trust? Cognition, 144, 76-90. 
https://doi.org/10.1016/j.cognition.2015.07.015

Khodyakov, D. (2007). Trust as a process: A three-dimensional approach. Sociology, 41(1), 115-132. https://doi.org/10.1177/0038038507072285

Ko, D. G. (2010). Consultant competence trust doesn't pay off, but benevolent trust does! Managing knowledge with care. Journal of Knowledge Management, 14(2), 202-213. https://doi.org/10.1108/13673271011032355

Kumalasari, F., \& Ahyani, L. N. (2012). Hubungan antara dukungan sosial dengan penyesuaian diri remaja di panti asuhan (The relationship of social support and self adjustment among teenager in orphanage). Jurnal Psikologi Pitutur, 1(1), 21-31.

Landrum, A. M., Mills, C. M., \& Johnston, A. M. (2013). When do children trust the expert? Benevolence information influences children's trust more than expertise. Developmental Science, 16(4), 622-638. https://doi.org/10.1111/desc.12059

Laursen, B., Noack, P., Wilder, D., \& Williams, V. (2000). Adolescent perceptions of reciprocity, authority, and closeness in relationships with mothers, fathers, and friends. International Journal of Behavioral Development, 24(4), 464-471. https://doi.org/10.1080/016502500750038017

Linden-Andersen, S., Markiewicz, D., \& Doyle, A. B. (2009). Perceived similarity among adolescent friends: The role of reciprocity, friendship quality, and gender. Journal of Early Adolescence, 29(5), 617-637. https://doi.org/10.1177/0272431608324372

Lindström, M. (2005). Social capital, the miniaturization of community and high alcohol consumption: A population-based study. Alcohol and Alcoholism, 40(6), 556-562. https://doi.org/10.1093/alcalc/agh190

Lunsky, Y., \& Benson, B. A. (2001). Association between perceived social support and strain, and positive and negative outcome for adults with mild intellectual disability. Journal of Intellectual Disability Research, 45(2), 106-114. https://doi.org/10.1046/j.1365-2788.2001.00334.x

Mayer, R. C., Davis, J. H., \& Schoorman, F. D. (1995). An integrative model of organizational trust. The Academy of Management Review, 20(3), 709-734. https://doi.org/10.2307/258792

McAllister, D. J. (1995). Affect-and-cognition-based trust formations for interpersonal cooperation in organizations. Academy of Management Journal, 38(1), 24-59. https://doi.org/10.2307/256727

Nielson, C. C. (1998). An empirical examination of the role of "closeness" in industrial buyer-seller relationships. European Journal of Marketing, 32(5/6), 441-463.

Palanski, M. E., Kahai, S. S., \& Yammarino, F. J. (2011). Team virtues and performance: An examination of transparency, behavioral integrity, and trust. Journal of Business Ethics, 99(2), 201-216. https://doi.org/10.1007/s10551-010-0650-7

Rotenberg, K. J. (2010). Interpersonal trust during childhood and adolescence. Cambridge University Press.

Rotenberg, K. J., Fox, C., Green, S., Ruderman, L., Slater, K., Stevens, K., \& Carlo, G. (2005). Construction and validation of a children's interpersonal trust belief scale. British Journal of Developmental Psychology, 23(2), 271-293. https://doi.org/10.1348/026151005X26192

Rus, A., \& Iglič, H. (2005). Trust, governance and performance: The role of institutional and interpersonal trust in SME Development. International Sociology, 20(3), 371-391. https://doi.org/10.1177/0268580905055481

Salazar, L. R. (2015). Exploring the relationship between compassion, closeness, trust, and social support in same-sex friendships. The Journal of Happiness \& Well-Being, 3(1), $15-29$. 
Shultz, G. P. (2007). Foreword. In Bits, bytes, and balance sheets: The new economic rules of engagement in a wireless world (pp. IX-XII). Hoover Institution.

Simmel, G. (2011). The philosophy of money: Third enlarged edition. Taylor \& Farncis eLibrary.

Simpson, J. A. (2007). Psychological foundations of trust. Current Directions in Psychological Science, 16(5), 264-268. https://doi.org/10.1111/j.14678721.2007.00517.x

Talwar, V., \& Renaud, S. J. (2010). Liar liar! Pants on fire: Detecting the trustworthiness of children's statements. In Interpersonal Trust during Childhood and Adolescence (pp. 177-199). Cambridge University Press.

Tanis, M., \& Postmes, T. (2005). A social identity approach to trust: Interpersonal perception, group membership and trusting behaviour. European Journal of Social Psychology, 35(3), 413-424. https://doi.org/10.1002/ejsp.256

Tschannen-Moran, M., \& Hoy, W. K. (2000). A multidisciplinary analysis of the nature, meaning, and measurement of trust. Review of Educational Research, 70(4), 547-593. https://doi.org/10.3102/00346543070004547

Turner, E. R. (2002). The differences in the levels of trust in male and female same sex friendships. Loyola University.

Van Lange, P. A. M., \& Balliet, D. (2015). Interdependence theory. In M. Mikulincer, P. R. Shaver, J. A. Simpson, \& J. F. Dovidio (Eds.), APA Handbook of Personality and Social Psychology, Volume 3: Interpersonal Relations (pp. 65-92). American Psychological Association.

Warris, A., \& Rafique, R. (2009). Trust in friendship: A comparative analysis of male and female university students. Bulletin of Education and Research, 31(2), 75-84.

Weber, K., Johnson, A., \& Corrigan, M. (2004). Communicating emotional support and its relationship to feelings of being understood, trust, and self-disclosure. Communication Research Reports, 21(3), 316-323. https://doi.org/10.1080/08824090409359994

Wu, C. C., Huang, Y., \& Hsu, C. L. (2014). Benevolence trust: A key determinant of user continuance use of online social networks. Information Systems and E-Business Management, 12(2), 189-211. https://doi.org/10.1007/s10257-013-0216-1

Xie, Y., \& Peng, S. (2009). How to repair customer trust after negative publicity: The roles of competence, integrity, benevolence, and forgiveness. Psychology \& Marketing, 26(7), 572-589. https://doi.org/10.1002/mar.20289

Ying, Y. W. (2008). The buffering effect of self-detachment against emotional exhaustion among social work students. Journal of Religion \& Spirituality in Social Work: Social Thought, 27, 27-146. https://doi.org/10.1080/15426430802114051

Yip, W., Subramanian, S. V, Mitchell, A. D., Lee, D. T. S., Wang, J., \& Kawachi, I. (2007). Does social capital enhance health and well-being? Evidence from rural China. Social Science \& Medicine, 64(1), 35-49. https://doi.org/10.1016/j.socscimed.2006.08.027 